\title{
Plasma Methionine Sulfoxide in Persons with Familial Alzheimer's Disease Mutations
}

\author{
John M. Ringman ${ }^{a} \quad$ Andrew T. Fithian ${ }^{a}$ Karen Gylys ${ }^{a, b}$ \\ Jeffrey L. Cummingsa,f Giovanni Coppola ${ }^{a}$ David Elashoffa,c \\ Domenico Praticog ${ }^{9}$ Jackob Moskovitz ${ }^{\mathrm{h}}$ Gal Bitan ${ }^{\mathrm{a}, \mathrm{d}, \mathrm{e}}$

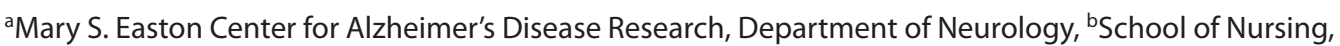 \\ 'Department of Medicine, 'Brain Research Institute, and ${ }^{\mathrm{e}}$ Molecular Biology Institute, University of California \\ at Los Angeles, Los Angeles, Calif.; ${ }^{f}$ Cleveland Clinic Lou Ruvo Center for Brain Health, Las Vegas, Nev.; \\ 9Temple University School of Medicine, Philadelphia, Pa., and hepartment of Pharmacology and Toxicology \\ School of Pharmacy, University of Kansas, Lawrence, Kans., USA
}

\author{
Key Words \\ Oxidative stress $\cdot$ Isoprostanes $\cdot$ Plasma $\cdot$ Superoxide \\ dismutase $\cdot$ Presenilin-1 - Amyloid $\beta$-protein precursor
}

and suggest that plasma oxidative stress markers may be useful for diagnosis of AD.

Copyright $\odot 2012$ S. Karger AG, Basel

\section{Introduction}

Oxidative stress in the brains of persons with Alzheimer's disease (AD) plays a central role in propagating [1] or even initiating [2] the illness. Free radicals and reactive oxygen species can overwhelm endogenous antioxidant defenses and damage cellular components including proteins, lipids, and DNA [1, 3, 4]. Oxidized forms of these molecules can be measured in biological fluids and serve as an index of the level of oxidative stress present [5]. Thus, increased levels of oxidative stress have been found in the brain, cerebrospinal fluid, and plasma of persons with late-onset $\mathrm{AD}$ [6].

Familial AD (FAD) is a relatively rare form of $\mathrm{AD}$ in which persons inheriting pathogenic mutations in the PSEN1, PSEN2, or APP genes are destined to develop AD at a relatively young age. Such mutations are thought to cause the disease through absolute or relative increase in the amount of the 42-amino acid-long form of amyloid $\beta$-protein $\left(\mathrm{A} \beta_{42}\right)$, a proteolytic cleavage product of amy-

\section{KARGER}

Fax +41613061234

E-Mail karger@karger.ch

www.karger.com
(C) 2012 S. Karger AG, Basel

$1420-8008 / 12 / 0334-0219 \$ 38.00 / 0$

Accessible online at:

www.karger.com/dem
Gal Bitan, PhD

David Geffen School of Medicine, University of California at Los Angeles Neuroscience Research Building 1, Room 451

635 Charles E. Young Drive South, Los Angeles, CA 90095-7334 (USA)

Tel. +1 310206 2082, E-Mail gbitan@mednet.ucla.edu 
loid $\beta$-protein precursor (APP). Though minor phenotypic differences exist between typical sporadic AD and certain cases of FAD [7], for the most part, similar mechanisms are thought to underlie the pathology in FAD and sporadic AD, including oxidative stress $[8,9]$. Previously, Ringman et al. [10] reported that F2-isoprostanes were elevated in the cerebrospinal fluid and plasma of persons carrying PSEN1 and APP mutations, suggesting a role for oxidative stress in FAD that may therefore represent a process that is downstream from $\mathrm{A} \beta_{42}$. F2-isoprostanes are products of nonenzymatic, free-radical catalyzed peroxidation of arachidonic and docosahexanoic acids, which can be used as biomarkers, and also are mediators of oxidative stress [11]. Recently, cerebrospinal fluid levels of F2-isoprostanes, though not other disease biomarkers, were found to decrease in response to antioxidant treatment in subjects with mild to moderate $\mathrm{AD}$ [12].

Nonenzymatic oxidation of methionine residues is a common reactive oxygen species-induced posttranslational modification of proteins indicative of oxidative damage [13]. Methionine-sulfoxide reductases (Msr) are enzymes that serve as an endogenous correction mechanism to reverse such protein oxidation [14]. Msr levels are lower in postmortem $\mathrm{AD}$ brain than in age-matched control brain [15]. In contrast, higher levels of Msr activity have been found in a double-transgenic mouse model of $\mathrm{AD}$ compared to wild-type mice [16], suggesting that up-regulation of Msr in early stages of AD may be a protective mechanism against oxidative stress, which fails at late stages as the disease progresses.

Recently, using a novel antibody specific for methionine sulfoxide (MetO)-containing proteins, Oien et al. [17] have shown an increase in MetO in the serum of a small number of persons diagnosed with $\mathrm{AD}$ compared to age-matched healthy individuals. Following up on these findings, here, we asked if MetO was elevated in the plasma of persons carrying FAD mutations.

\section{Methods}

\section{Subjects}

Plasma was collected from 31 persons from families harboring PSEN1 or APP mutations. All subjects underwent in-depth clinical, imaging, and biochemical assessments. Twenty-three subjects were from 10 families with known PSEN1 mutations (A431E substitution [18, 19], $\mathrm{n}=8$; G206A substitution [20], $\mathrm{n}$ $=1 ; \mathrm{S} 212 \mathrm{Y}$ substitution [21], $\mathrm{n}=1$ ) and 8 were from 2 families harboring APP mutations (both V717I [22]) (table 1).

The Clinical Dementia Rating Scale (CDR) [23] was performed with an unrelated informant and the subject, with
Table 1. Demographic data

\begin{tabular}{|c|c|c|c|}
\hline & $\begin{array}{l}\text { FAD MCs } \\
(\mathrm{n}=19)\end{array}$ & $\begin{array}{l}\text { NCs } \\
(\mathrm{n}=12)\end{array}$ & $\mathrm{p}$ \\
\hline Mean age $\pm S D$, years & $36.2 \pm 9.7$ & $38.8 \pm 11.5$ & $0.51^{\mathrm{a}}$ \\
\hline $\begin{array}{l}\text { Mean adjusted age } \pm \\
\text { SD, years }\end{array}$ & $-9.1 \pm 10.4$ & $-6.8 \pm 15.9$ & $0.65^{\mathrm{a}}$ \\
\hline CDR sum of boxes score & $2.5(5.2)$ & $0.3(0.3)$ & $0.08^{\mathrm{a}}$ \\
\hline Gender, female, n (\%) & $14(74)$ & $9(75)$ & $1.00^{\mathrm{b}}$ \\
\hline Gene mutated in family & $\begin{array}{l}A P P=5, \\
P S E N 1=14\end{array}$ & $\begin{array}{l}A P P=3 \\
P S E N 1=9\end{array}$ & $1.00^{\mathrm{b}}$ \\
\hline $\begin{array}{l}\text { APOE genotype } 2 / 3 \text {, } \\
3 / 3,3 / 4, \mathrm{n}\end{array}$ & $5,11,3$ & $1,7,4$ & $0.33^{\mathrm{c}}$ \\
\hline Smokers, $\mathrm{n}(\%)^{\mathrm{d}}$ & $1(6)$ & $5(42)$ & $0.06^{\mathrm{b}}$ \\
\hline
\end{tabular}

a Two-sided t test.

b Two-sided Fisher's exact test.

${ }^{c}$ Pearson $\chi^{2}$ test.

d Smoking data is missing for 3 subjects.

scores of $0.5,1,2$, and 3 representing questionable, mild, moderate, and severe stages of dementia, respectively (table 1). A sum of boxes score also was calculated as an index of disability with a wider range. In all but 4 demented subjects and 2 subjects who had undergone clinical presymptomatic testing, ratings were performed blind to subjects' genetic status. Subjects were informed that they would be tested for $A P O E$ genotype and the FAD mutation for which they were at risk but in the context of the research protocol would not be told the result. All subjects signed written, informed consent. All study procedures were approved by the Institutional Review Board at UCLA.

Age of onset of disease in FAD can be consistent within, but vary between families $[18,24]$. Therefore, to compare subjects relative to the expected onset of clinical disease, their ages relative to the median age of disease diagnosis in their families was calculated and designated 'adjusted age' (table 1).

\section{Genetic Testing}

DNA was extracted and apolipoprotein E genotyping performed using standard techniques.

Presenilin-1. The presence of the A431E substitution in PSEN1 was assessed using restriction fragment length polymorphism analysis. The subject carrying the S212Y PSEN1 mutation was ascertained using a commercial test where the open reading frame of the coding region of the PSEN1 gene was sequenced. The presence or absence of the G206A substitution in PSEN1 was assessed directly with bidirectional sequencing.

$A P P$. The presence of the V717I substitution in $A P P$ was assessed with direct sequencing.

\section{Blood Collection}

Blood was drawn in the morning in a fasting state. Thirty cubic centimeters of plasma was centrifuged, aliquoted into 
0.5-ml siliconized polypropylene Eppendorf tubes, and stored at $-80^{\circ} \mathrm{C}$ within $2 \mathrm{~h}$ of being drawn. Plasma samples were coded using unique identifiers and stored at $-80^{\circ} \mathrm{C}$.

\section{Western Blot Measurement of MetO}

The amount of protein in each sample was measured using a standard BCA protein assay (Bio-Rad, Hercules, Calif., USA). Then, 50 ng protein was mixed with glycine sample buffer (Invitrogen, Carlsbad, Calif., USA) containing $5 \% \beta$-mercaptoethanol, and fractionated by SDS-PAGE using $4-20 \%$ gradient Tris-glycine gels (Invitrogen). The proteins then were transferred to nitrocellulose membranes (Invitrogen), blocked using ECL blocking reagent (AmershamGE Healthcare, Piscataway, N.J., USA) and incubated with an anti-MetO polyclonal antibody, which had been raised against oxidized methionine-rich zein protein (anti-MetO-DZS18) [17]. The membranes were washed, incubated with a goat antirabbit secondary antibody, washed again, and developed by enhanced chemiluminescence (Amersham-GE Healthcare). Images were recorded using an AlphaImager HP system (Cell Biosciences, Santa Clara, Calif., USA). MetO-reactive bands were quantified densitometrically using ImageJ (available at http://rsbweb.nih.gov/ij/) and normalized to the entire lane. Samples from each subject were analyzed in four independent experiments and the data averaged.

\section{Isoprostane Measurement}

A subset of subjects $(n=15)$ had plasma F2-isoprostane levels measured. Samples were spiked with internal standard d4-8,12-iso-iPF2 $\alpha$-VI (F2-isoprostanes, or iPF2a) and extracted on a C18 cartridge column. The eluate was purified by thin-layer chromatography. The trimethylsilyl derivative then was made and the samples were assayed by chemical ionization gas chromatography-mass spectrometry in negative ion mode [25].

\section{Multiple Protein Analysis}

Plasma samples from 30 of the subjects were analyzed by Rules Based Medicine, Inc., who measured the levels of 77 proteins using multiplex immune assays on a Luminex platform. Briefly, microspheres were color-coded by varying the ratio of a pair of dyes impregnated into beads. Each bead set was coated with a reagent specific to the molecules of interest, allowing the capture and detection of specific analytes. Assays were configured such that a capture antibody was covalently coupled to the surface of the beads. Following sample incubation and washes, a fluorescently labeled detection antibody then was bound. The complexes were analyzed in the Luminex instrument, which passes the beads past a pair of lasers that detect the reporter dye on the detection antibody and the dye ratio simultaneously. A total of eight multiplex assays, comprising 77 target molecules, were run on each plasma sample. Each multiplex run included analyte-specific standards and controls. Plasma levels of superoxide dismutase 1 (SOD1) were analyzed for the current paper.

Methionine Sulfoxide in Familial

Alzheimer's Disease

\section{Statistical Analysis}

Levels of MetO reactivity (see below) were compared between FAD mutation carriers (MCs) and noncarriers (NCs) by an independent-samples $t$ test. Considering the non-normality of the distribution of MetO reactivity, values were log-transformed and the $t$ test repeated to confirm the results. MetO reactivity was analyzed for possible interaction with smoking (smokers vs. nonsmokers), gene (APP vs. PSEN1), MC status (present or absent), or $A P O E$ genotype variables using oneway ANOVA. Additionally, we examined the combined effect of gene and mutation status on MetO reactivity using twoway ANOVA. Spearman's correlations were sought between age, adjusted age, and CDR sum of boxes score and MetO reactivity for the population as a whole as well as separately for MCs and NCs. Demographic characteristics were compared between MCs and NCs by t tests and $\chi^{2}$ tests as appropriate. Correlations were sought between SOD1, F2-isoprostane, and MetO reactivity using Spearman correlation.

\section{Results}

Of the 31 subjects analyzed, 19 were MCs (PSEN1 = $14, A P P=5)$ and 12 were NCs. Among MCs, 12 were asymptomatic (CDR score $=0), 4$ had questionable or minor cognitive impairment $(\mathrm{CDR}$ score $=0.5)$, and 1 subject each had mild, moderate, and severe dementia. Subjects did not differ in regard to mean absolute age or adjusted age.

We asked whether markers of oxidative stress, including plasma MetO and isoprostane levels, correlated with the genotype and/or the clinical status of the subjects participating in the study. In Western blot analysis using a novel anti-MetO antibody, we observed four major bands at 120,135, 160, and $200 \mathrm{kDa}$ (fig. 1a). The $\sim 200-\mathrm{kDa}$ band contained several bands with a wide range of variability. Two independent operators, blinded to mutation status, were asked to find patterns in the data and reached a consensus dividing the 31 samples into four groups (fig. 1a). Group I $(n=5)$ was characterized by high mean abundance of the $120-\mathrm{kDa}$ and low mean abundance of the $\sim 200-\mathrm{kDa}$ band compared to the other three groups. Group II $(\mathrm{n}=6)$ had the highest mean abundance of the $135-\mathrm{kDa}$ band and a low abundance of the $120-\mathrm{kDa}$ band. In contrast, groups III $(\mathrm{n}=13)$ and IV $(n=7)$ both had low mean abundance of the $135-\mathrm{kDa}$ band. In addition, group IV had a very low abundance of the $120-\mathrm{kDa}$ band (fig. 1b). The $120-\mathrm{kDa}$ band was the most distinctive feature among the groups (fig. 1), and therefore was chosen as a criterion for quantitative analysis of the different patterns observed. To standardize this measure among subjects, the densitometric value 


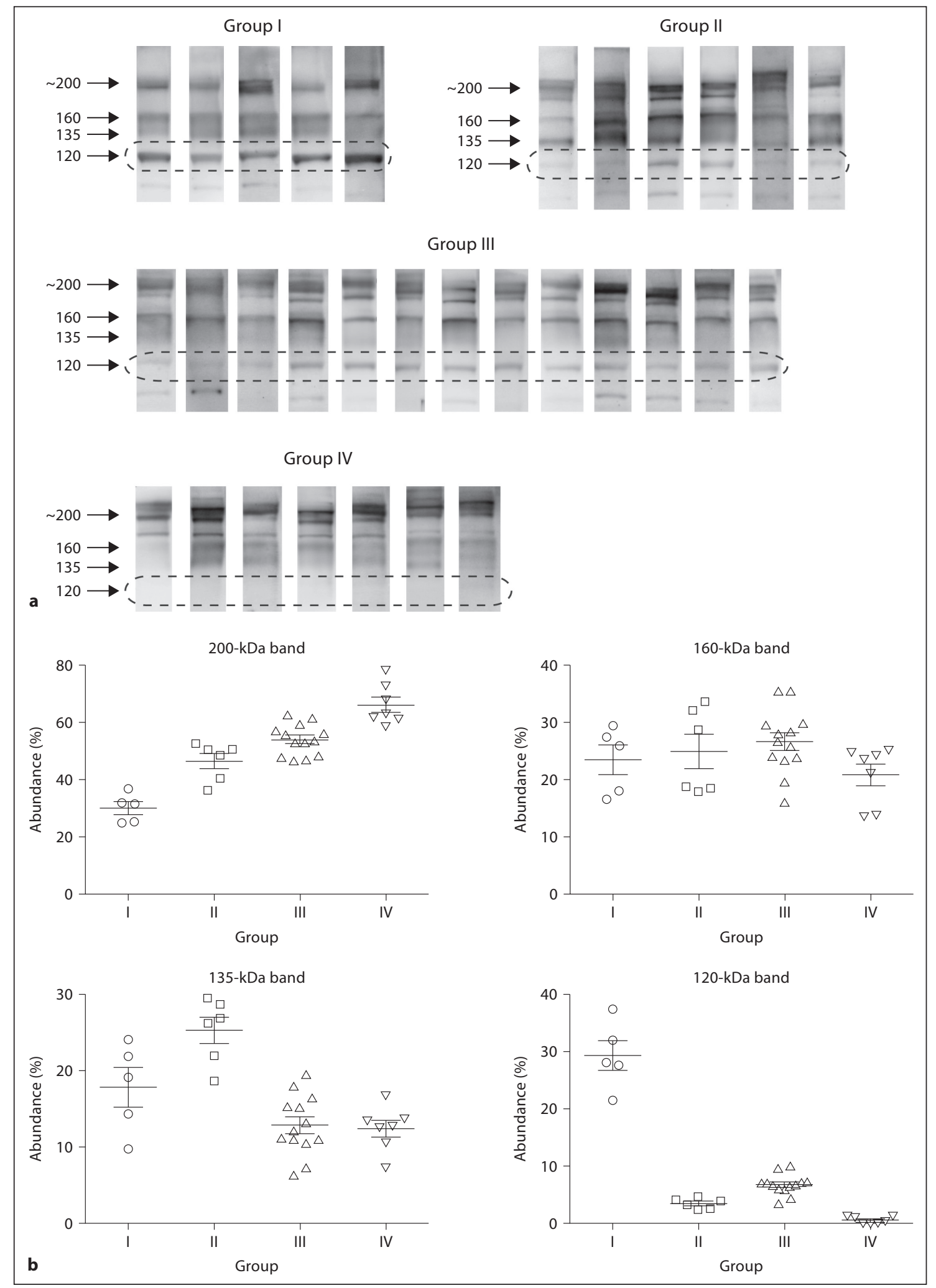

Fig. 1. Western blot analysis of plasma proteins by anti-MetO antibody. a MetO-reactive bands were divided into four groups based on pattern recognition by 2 investigators blinded to mutation or disease status. $\mathbf{b}$ Densitometric analysis of the four prominent gel bands observed. 


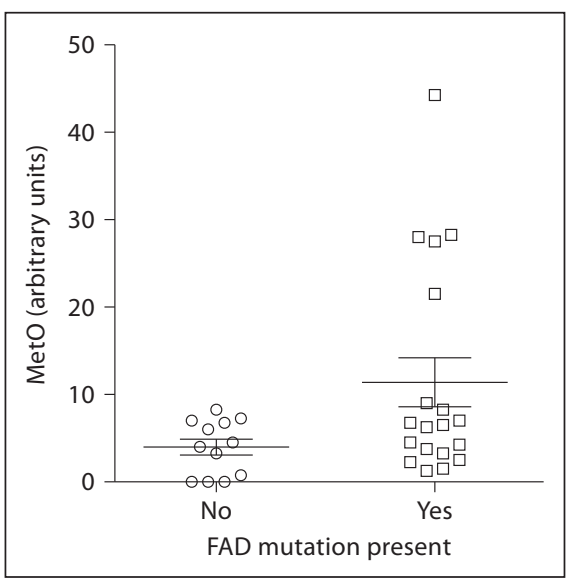

Fig. 2. Levels of MetO reactivity in FAD MCs and NCs quantified densitometrically (Student's t test, $\mathrm{p}=0.02$ ).

(arbitrary densitometric units) of the $120-\mathrm{kDa}$ band was normalized to the entire lane and defined as 'MetO reactivity', which was used for comparison among subjects.

The MetO reactivity was found to be significantly greater in FAD MCs than NCs $(11.4 \pm 2.8$ vs. $4.0 \pm 3.1$, $\mathrm{p}=0.02$, fig. 2 ). When the MetO reactivity was log-transformed, this difference was maintained (0.92 vs. $0.57, \mathrm{p}=$ 0.02). Moreover, comparison between the 12 asymptomatic FAD MCs and the NCs showed an even higher difference in MetO reactivity in the former (13.1 \pm 13.8 vs. $4.0 \pm 3.1, \mathrm{p}=0.045)$ and the difference remained significant when the data were log-transformed $(p=0.02)$. In contrast, there were no significant relationships between CDR sum of boxes scores, current smoking, age, adjusted age, or mutation type and $\mathrm{MetO}$ reactivity.

The two markers of oxidative stress, MetO reactivity and F2-isoprostane levels, showed high positive correlation ( $\mathrm{r}=0.81, \mathrm{p}<0.001$, fig. 3 ). Interestingly, we also found positive correlation between MetO reactivity and plasma levels of SOD1 ( $\mathrm{r}=0.52, \mathrm{p}=0.004$, fig. 4$)$.

\section{Discussion}

Our Western blot analysis using a novel anti-MetO antibody showed four different patterns among the 31 patients. The anti-MetO antibody recognizes MetO residues depending on their exposure on the protein surface. Previously, it was shown that oxidation of Met to MetO may cause major conformational rearrangements leading to exposure of Met residues that are buried in their native, reduced form [26]. It is difficult, however, to predict whether this happens in every specific epitope. Thus, the

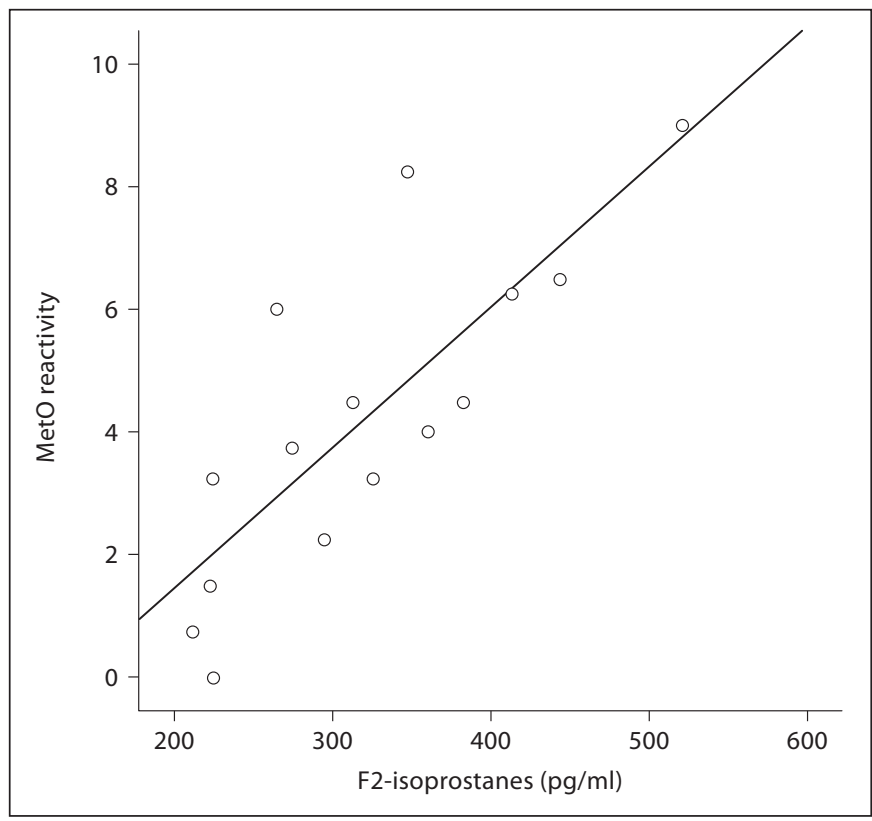

Fig. 3. Correlation between F2-isoprostane levels and MetO reactivity (Spearman's correlation, $\mathrm{r}=0.81, \mathrm{p}<0.001$ ).

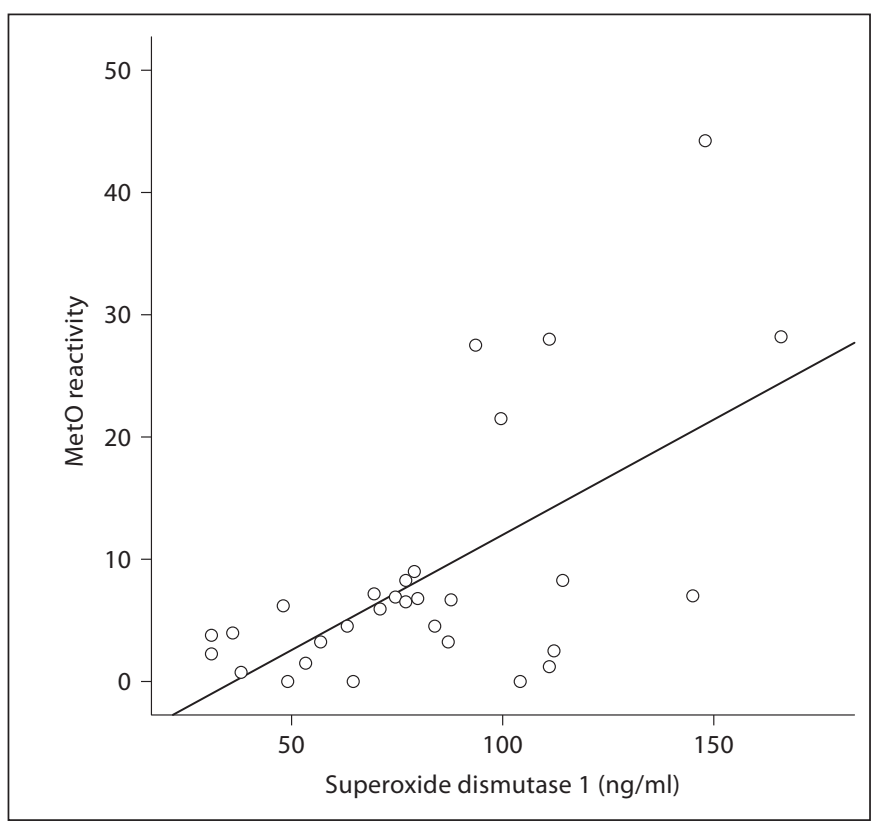

Fig. 4. Correlation between SOD1 levels and MetO reactivity (Spearman's correlation, $\mathrm{r}=0.52, \mathrm{p}=0.004$ ).

antibody is believed to be specific to the sulfoxide group of MetO [17], but deciphering the specific binding epitope in a protein of interest will need to be addressed in future studies. 
In particular, we found elevated MetO reactivity, measured densitometrically in a $120-\mathrm{kDa}$ band using an anti-MetO antibody (fig. 1), in persons carrying FAD mutations. This effect appeared to be driven largely by 5 of the FAD MCs in group I, who had high MetO reactivity (fig. 1b, 2). Of these persons, 4 carried a PSEN1 A431E mutation and 1 carried an APP V717I mutation. Notably, all NCs had low MetO reactivity and the only 3 subjects for whom MetO reactivity was below detectable levels were NCs. Thus, the presence of a prominent $120-\mathrm{kDa}$ band in our assay correlated in all cases with an FAD mutation, though the absence of this band did not necessarily indicate the absence of mutation. The findings suggest that high plasma MetO reactivity may be indicative of an ongoing disease process accompanied by oxidative stress, which fails to be mitigated by the Msr system in FAD MCs.

We did not find clear correlations between MetO reactivity and age, adjusted age, or disease status as 4 of the 5 subjects with the highest MetO reactivity levels were young and asymptomatic (CDR score of 0 ) and 1 had moderate dementia (CDR score of 2). It is possible that correlations would be found in a larger sample, which was not available for this study.

The strong positive correlation between MetO reactivity and F2-isoprostane levels supports the role of oxidative stress in FAD and suggests that although the pathology occurs in the brain, it is evident also in the periphery in the form of elevated lipid peroxidation (isoprostanes) and protein oxidation (MetO) markers. Unfortunately, F2-isoprostane levels were not available for the 5 subjects for whom MetO levels were highest. We therefore cannot conclude at this point that the correlation found is maintained at such levels.

The positive correlation between MetO reactivity and plasma SOD1 levels is an intriguing finding. SOD1 is a cytosolic protein and its origin in the plasma of the population studied here is uncertain. The correlation found may indicate an increase of SOD1 production and secretion into the plasma as a compensatory response to oxidative stress, or reflect elevated enzyme release due to enhanced cell death. SOD1 is a highly stable protein [27], suggesting that it may have a long half-life [28] compared with other cytoplasmic proteins released following cell death. SOD1 plays an important role in preventing mitochondrial-linked cell death $[29,30]$. Accordingly, oxidative stress may prompt cells to respond by up-regulating SOD1 as a protective mechanism against oxidative damage [31, 32]. Failure of this response mechanism may increase the release of SOD1 through oxidative damage to cellular membranes.

The finding of increased MetO reactivity in asymptomatic persons carrying FAD mutations and the correlation between MetO reactivity and other indices of oxidative stress supports an important role for oxidative stress early in the pathogenesis of FAD. As overproduction of $A \beta_{42}$ is thought to be the critical factor causing the disease in persons with FAD-linked mutations, our findings suggest that though oxidative stress is an early pathologic process in $\mathrm{AD}$, it occurs downstream of the $A \beta$-induced neuronal injury.

\section{Acknowledgments}

This study was supported by PHS K08 AG-22228, California DHS No. 04-35522, and the Shirley and Jack Goldberg Trust, Alzheimer's Association Grant IIRG-0758334, NIH/NIA Alzheimer's Disease Research Center Grant P50 AG-16570, General Clinical Research Centers Program M01-RR00865, and an Alzheimer's Disease Research Center of California grant, the Sidell Kagan Foundation, and the Easton Consortium for Alzheimer's Disease Drug Discovery and Biomarker Development.

\section{Disclosure Statement}

The authors report no conflict of interest.

\section{References}

1 Lovell MA, Markesbery WR: Oxidative damage in mild cognitive impairment and early Alzheimer's disease. J Neurosci Res 2007;85: 3036-3040. DOI: 10.1002/jnr.21346

-2 Perry G, Nunomura A, Hirai K, Zhu XW, Perez M, Avila J, Castellani RJ, Atwood CS, Aliev G, Sayre LM, Takeda A, Smith MA: Is oxidative damage the fundamental pathogenic mechanism of Alzheimer's and other neurodegenerative diseases? Free Radic Biol Med 2002;33:1475-1479.
-3 Montine TJ, Neely MD, Quinn JF, Beal MF, Markesbery WR, Roberts LJ, Morrow JD: Lipid peroxidation in aging brain and $\mathrm{Al}$ zheimer's disease. Free Radic Biol Med 2002; 33:620-626.

4 Ancelin ML, Christen Y, Ritchie K: Is antioxidant therapy a viable alternative for mild cognitive impairment? Examination of the evidence. Dement Geriatr Cogn Disord 2007; 24:1-19.
5 Polidori MC, Mattioli P, Aldred S, Cecchetti R, Stahl W, Griffiths H, Senin U, Sies H, Mecocci P: Plasma antioxidant status, immunoglobulin $G$ oxidation and lipid peroxidation in demented patients: relevance to Alzheimer disease and vascular dementia. Dement Geriatr Cogn Disord 2004;18: 265-270.

6 Behl C: Oxidative stress in Alzheimer's disease: implications for prevention and therapy. Subcell Biochem 2005;38:65-78.
Ringman/Fithian/Gylys/Cummings/ Coppola/Elashoff/Pratico/Moskovitz/ Bitan 
$>7$ Ringman JM, Romano JD, Medina LD, Rodriguez-Agudelo Y, Schaffer B, Varpetian A, Ortiz F, Fitten LJ, Cummings JL, Baloh RW: Increased prevalence of significant recurrent headache in preclinical familial Alzheimer's disease mutation carriers. Dement Geriatr Cogn Disord 2008;25:380-384.

$>8$ Velez-Pardo C, Jimenez Del Rio M, Lopera F: Familial Alzheimer's disease: oxidative stress, beta-amyloid, presenilins, and cell death. Gen Pharmacol 1998;31:675-681.

$\checkmark 9$ Mosconi L, Pupi A, De Leon MJ: Brain glucose hypometabolism and oxidative stress in preclinical Alzheimer's disease. Ann NY Acad Sci 2008;1147:180-195.

$\checkmark 10$ Ringman JM, Younkin SG, Pratico D, Seltzer W, Cole GM, Geschwind DH, RodriguezAgudelo Y, Schaffer B, Fein J, Sokolow S, Rosario ER, Gylys KH, Varpetian A, Medina LD, Cummings JL: Biochemical markers in persons with preclinical familial Alzheimer disease. Neurology 2008;71:85-92.

11 Montuschi P, Barnes PJ, Roberts LJ, 2nd: Isoprostanes: markers and mediators of oxidative stress. FASEB J 2004;18:1791-1800.

12 Galasko DR, Peskind E, Clark CM, Quinn JF, Ringman JM, Jicha GA, Cotman C, Cottrell B, Montine TJ, Thomas RG, Aisen P: Antioxidants for Alzheimer disease: a randomized clinical trial with cerebrospinal fluid biomarker measures. Arch Neurol 2012.

-13 Moskovitz J, Berlett BS, Poston JM, Stadtman ER: The yeast peptide-methionine sulfoxide reductase functions as an antioxidant in vivo. Proc Natl Acad Sci USA 1997;94 9585-9589.

14 Oien DB, Moskovitz J: Substrates of the methionine sulfoxide reductase system and their physiological relevance. Curr Top Dev Biol 2008;80:93-133.

15 Gabbita SP, Aksenov MY, Lovell MA, Markesbery WR: Decrease in peptide methionine sulfoxide reductase in Alzheimer's disease brain. J Neurochem 1999;73: $1660-1666$

>16 Moskovitz J, Maiti P, Lopes DH, Oien DB, Attar A, Liu T, Mittal S, Hayes J, Bitan G: Induction of methionine-sulfoxide reductases protects neurons from amyloid $\beta$-protein insults in vitro and in vivo. Biochemistry 2011; 50:10687-10697.

- 17 Oien DB, Canello T, Gabizon R, Gasset M, Lundquist BL, Burns JM, Moskovitz J: Detection of oxidized methionine in selected proteins, cellular extracts and blood serums by novel anti-methionine sulfoxide antibodies. Arch Biochem Biophys 2009;485:35-40.
18 Murrell J, Ghetti B, Cochran E, Macias-Islas MA, Medina L, Varpetian A, Cummings JL, Mendez MF, Kawas C, Chui H, Ringman JM: The A431E mutation in PSEN1 causing familial Alzheimer's disease originating in Jalisco State, Mexico: an additional fifteen families. Neurogenetics 2006;7:277-279.

19 Yescas P, Huertas-Vazquez A, VillarrealMolina MT, Rasmussen A, Tusié-Luna MT, López M, Canizales-Quinteros S, Alonso ME: Founder effect for the Ala431Glu mutation of the presenilin 1 gene causing early-onset Alzheimer's disease in Mexican families. Neurogenetics 2006;7:195-200.

20 Athan ES, Williamson J, Ciappa A, Santana V, Romas SN, Lee JH, Rondon H, Lantigua RA, Medrano M, Torres M, Arawaka S, Rogaeva E, Song YQ, Sato C, Kawarai T, Fafel KC, Boss MA, Seltzer WK, Stern Y, St George-Hyslop P, Tycko B, Mayeux R: A founder mutation in presenilin 1 causing early-onset Alzheimer disease in unrelated Caribbean Hispanic families. JAMA 2001;286: 2257-2263.

21 Ringman JM, Gylys KH, Medina LD, Fox M, Kepe V, Flores DL, Apostolova LG, Barrio JR, Small G, Silverman DH, Siu E, Cederbaum S, Hecimovic S, Malnar M, Chakraverty S, Goate AM, Bird TD, Leverenz JB: Biochemical, neuropathological, and neuroimaging characteristics of early-onset Alzheimer's disease due to a novel psen 1 mutation. Neurosci Lett 2011;487:287-292.

22 Mullan M, Tsuji S, Miki T, Katsuya T, Naruse S, Kaneko K, Shimizu T, Kojima T, Nakano I, Ogihara T, et al: Clinical comparison of Alzheimer's disease in pedigrees with the codon 717 Val->Ile mutation in the amyloid precursor protein gene. Neurobiol Aging 1993;14:407-419.

23 Morris JC: Clinical dementia rating: a reliable and valid diagnostic and staging measure for dementia of the Alzheimer type. Int Psychogeriatr 1997;9(suppl 1):173-176; discussion 177-178.

4 Fox NC, Kennedy AM, Harvey RJ, Lantos PL, Roques PK, Collinge J, Hardy J, Hutton M, Stevens JM, Warrington EK, Rossor MN: Clinicopathological features of familial Alzheimer's disease associated with the M139V mutation in the presenilin 1 gene: pedigree but not mutation specific age at onset provides evidence for a further genetic factor. Brain 1997;120:491-501.
25 Pratico D, Clark CM, Lee VM, Trojanowski JQ, Rokach J, Fitzgerald GA: Increased 8,12-iso-iPF2alpha-VI in Alzheimer's disease: correlation of a noninvasive index of lipid peroxidation with disease severity. Ann Neurol 2000;48:809-812.

26 Bitan G, Tarus B, Vollers SS, Lashuel HA, Condron MM, Straub JE, Teplow DB: A molecular switch in amyloid assembly: $\mathrm{Met}^{35}$ and amyloid $\beta$-protein oligomerization. J Am Chem Soc 2003;125:15359-15365.

$>27$ Rakhit R, Cunningham P, Furtos-Matei A, Dahan S, Qi XF, Crow JP, Cashman NR, Kondejewski LH, Chakrabartty A: Oxidation-induced misfolding and aggregation of superoxide dismutase and its implications for amyotrophic lateral sclerosis. J Biol Chem 2002;277:47551-47556.

-28 Cudkowicz ME, Warren L, Francis JW, Lloyd KJ, Friedlander RM, Borges LF, Kassem N, Munsat TL, Brown RH Jr: Intrathecal administration of recombinant human superoxide dismutase 1 in amyotrophic lateral sclerosis: a preliminary safety and pharmacokinetic study. Neurology 1997;49: 213-222.

29 Liang HL, Sedlic F, Bosnjak Z, Nilakantan $\mathrm{V}$ : SOD1 and MitoTEMPO partially prevent mitochondrial permeability transition pore opening, necrosis, and mitochondrial apoptosis after ATP depletion recovery. Free Radic Biol Med 2010;49:1550-1560.

30 Li Q, Sato EF, Zhu X, Inoue M: A simultaneous release of SOD1 with cytochrome c regulates mitochondria-dependent apoptosis. Mol Cell Biochem 2009;322:151-159.

31 Rojo AI, Salinas M, Martin D, Perona R, Cuadrado A: Regulation of $\mathrm{Cu} / \mathrm{Zn}$-superoxide dismutase expression via the phosphatidylinositol 3 kinase/Akt pathway and nuclear factor-kappaB. J Neurosci 2004;24: 7324-7334.

32 Lopez IA, Acuna D, Beltran-Parrazal L, Lopez IE, Amarnani A, Cortes M, Edmond $\mathrm{J}$ : Evidence for oxidative stress in the developing cerebellum of the rat after chronic mild carbon monoxide exposure $(0.0025 \%$ in air). BMC Neurosci 2009;10:53. 